\title{
Effects of Hydrochloric Acid Catalyst Concentration on Crystallization of Sol-Gel Derived $\mathrm{CaMgSi}_{2} \mathrm{O}_{6}$ Gels
}

\author{
Akinori Katsui, Kazutoshi Iwamoto and Hiroaki Matsushita \\ Dept. of Material Science and technology, School and High-Technology for Human Welfare, 317 Nishino, Numazu 410-0321.
}

Received March 16, 2001

\begin{abstract}
SYNOPSIS
The sol-gel-derived diopside gels of the composition $25 \mathrm{~mol} \% \mathrm{CaO}-25 \mathrm{~mol} \% \mathrm{MgO}-50 \mathrm{~mol} \% \mathrm{SiO}_{2}$ are prepared adding hydrochloric acid of 1 to $4 \mathrm{~mol} / \mathrm{dm}^{3}$ concentration in the basic step, and the crystallization behavior of the gels during heating is investigated using thermal differential analysis (DTA-TG), X-ray diffraction and Fourier transform infrared spectroscopy. The results show that the addition of hydrochloric acid leads to lower temperatures of glass formation and crystallization, due to the ristriction of calcium carbonate formation, and that the suitable concentration for the single phase crystallization is $3 \mathrm{~mol} / \mathrm{dm}^{3}$.
\end{abstract}

KEY WORDS

Diopside, biomaterial, sol-gel, crystallization, Hydrochloric acid concentration, single phase

\section{Introduction}

$\mathrm{CaMgSi}_{2} \mathrm{O}_{6}$ (Diopside) glass-ceramics in the system $\mathrm{CaO}-\mathrm{MgO}-\mathrm{SiO}_{2}$ have high biologically affinity, high mechanical strength and press-formability ${ }^{1-4)}$, and therefore have attracted interest as potential biomaterials. Katsui et $\mathrm{al}^{5}{ }^{5}$ synthesized the diopside ceramics by heating the gels prepared using a sol-gel route from $\mathrm{Ca}$ metal, $\mathrm{Mg}$ metal and tetramethoxysilane. In this gel method, hydrochloric acid is added as a catalyst to the mixture solution during hydrolysing, with a decided amount of water. They found ${ }^{6}$ that the use of hydrochloric acid is particularly necessary for the preparation of diopside ceramics without other crystallizing phases and subsequently develops the glassceramics with desirable properties through a sol-gel route. Hence, investigations of optimizing conditions adding hydrochloric acid catalyst are of interest.

In the present work, the crystallization of $\mathrm{CaMgSi}_{2} \mathrm{O}_{6}$ gels was studied as a function of hydrochloric acid concentration, using DTA-TG, X-ray diffraction (XRD), and Fourier transform infrared spectroscopy (FTIR).

\section{Experimental procedure}

The gels with a molar ratio of $1: 1: 2$ for $\mathrm{CaO}: \mathrm{MgO}$ : $\mathrm{SiO}_{2}$ were prepared by the sol-gel process using $\mathrm{Ca}$ metal, $\mathrm{Mg}$ metal and tetramethoxysilane $\mathrm{Si}\left(\mathrm{OCH}_{3}\right)_{4}$ (Tokyo Kasei) as starting materials. Firstly $0.025 \mathrm{~mol}$ of $\mathrm{Mg}$ metal (Wako) was dissolved in $10 \mathrm{ml}$ of dehydrated methanol and $20 \mathrm{ml}$ of tetrahydrofuran in a glass container, and next, $0.025 \mathrm{~mol}$ of $\mathrm{Ca}$ (Wako) metal was dissolved in the solution. Secondly, $0.05 \mathrm{~mol}$ of tetramethoxysilane was added to the resultant solution, following by stirring at room temperature. $10 \mathrm{ml}$ of methanol was added to the solution poured into another glass container, and stirred. Next, $1 \mathrm{~mol} / \mathrm{dm}^{3}$ (sample No.; \#S-1), $2 \mathrm{~mol} / \mathrm{dm}^{3}$ (\#S-2), $3 \mathrm{~mol} / \mathrm{dm}^{3}$ (\#S-3) and $4 \mathrm{~mol} / \mathrm{dm}^{3}$ (\#S-4) of hydrochloric acid was added to the solution, with $0.3 \mathrm{~mol}$ of water. Furthermore, the gels with only $0.3 \mathrm{~mol}$ (\#S-5) and $0.32 \mathrm{~mol}$ (\#S-6) of water, not adding hydrochloric acid, were also prepared. Finally the gels obtained were dried at room temperature for a few days.

The dried gels were heated at the rate of about $0.06 \mathrm{~K} / \mathrm{s}$ to temperatures in the range 623 to $1473 \mathrm{~K}$ in air. The diopside glass formation and crystallization of the gels in the heating process were investigated by means of DTATG, X-ray powder diffraction and IR spectroscopy. Rigaku Denki TG8120 was used for DTA-TG analysis. The heating rate of dried gels was $0.33 \mathrm{~K} / \mathrm{s}$. X-ray powder diffraction patterns were obtained on a Mac Science MXP3 diffractometer system employing $\mathrm{Cu} \mathrm{K} \alpha_{1}(\lambda=1.5405 \mathrm{~A})$. The IR spectra were obtained on a Perkin Elmer 1720X Fourier Transform Infrared Spectrometer using the $\mathrm{KBr}$ pellet method.

\section{Results and Discussion}

Fig. 1 shows the TG-DTA curve for three kind of dried gels (\#S-1,\#S-3 and \#S-6) from room temperature to $1723 \mathrm{~K}$. 
The DTA curves of all the three gels showed an endothermic peak at $373-473 \mathrm{~K}$, due to the removal of physically bound water and some residual organic matter, followed by a wide exothermic peak around $573 \mathrm{~K}$. This exothermic peak is probably due to the combustion of the unreacted organic groups of the alkoxides. Small endothermic peaks at 873$973 \mathrm{~K}$ on the DTA, depending on hydrochloric acid concentration, may be attributed to the beginning of glass formation process.

The first clearly detectable exothermic peak was attributed to the crystallization of diopside. The peak temperature was $1130.7 \mathrm{~K}$ and $1097.6 \mathrm{~K}$ for hydrochloric acid concentration of $1 \mathrm{~mol} / \mathrm{dm}^{3}$ (\#S-1) and $3 \mathrm{~mol} / \mathrm{dm}^{3}$ (\#S-3), respectively. The larger the hydrochloric acid concentration, the lower the crystallization temperature of diopside. The crystallization temperature for gel (\#S-6) not adding hydrochloric acid was $1148.3 \mathrm{~K}$. Larger amounts of water increased the crystallization temperature of diopside. An endothermic peak was observed at around $1653 \mathrm{~K}$ for the three gels, due to the melting of diopside.

A crystallization sequence for the gel of \#S-3 heated in air, is given in Fig. 2. On heating at $623-873 \mathrm{~K}$, calcite (JCPDS-50586) is observed, although the peak intensity was decreased with heating temperature. At $923 \mathrm{~K}$, calcite

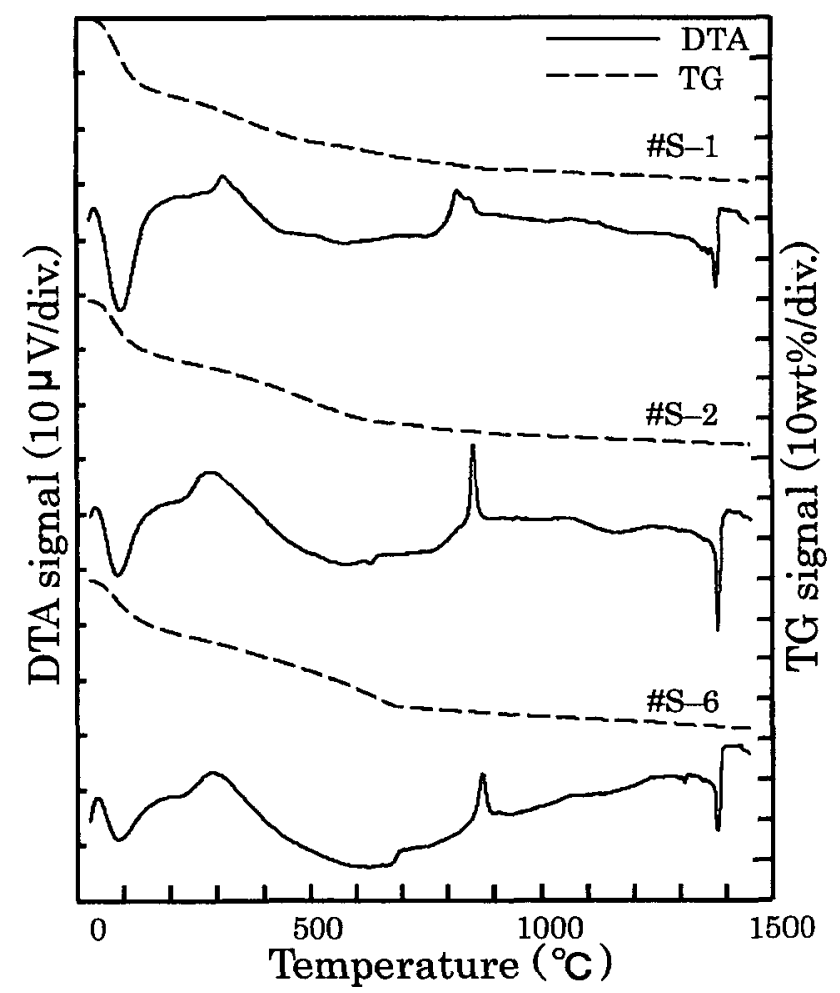

Fig.1 DTA-TG curve of dried gel using different hydrochloric acid catalyst concentration, heated at $0.33 \mathrm{~K} / \mathrm{s}$ in air.

(a) $1 \mathrm{~mol} / \mathrm{dm}^{3}$ (\#S-1), (b) $3 \mathrm{~mol} / \mathrm{dm}^{3}$ (\#S-3),

(c) without hydrochloric acid (\#S-6). decreases drastically and two new peaks appear, in addition to extremely broadened peak around $2 \theta=30^{\circ}$. Former two peaks were equal to the diffraction position of the 221 and 002/202 planes of diopside. Thus, formation of the glassy diopside phase was nearly completed and the crystallization began at $923 \mathrm{~K}$. All of the peaks at temperatures from $973 \mathrm{~K}$ to $1473 \mathrm{~K}$ can be indexed as monoclinic diopside. As the heat temperature is increased, the peaks attributed to diopside become more intense. In the gel of \#S-4, the same result as \#S-3 was obtained. The results indicates that the gels change as calcium carbonate $\rightarrow$ diopside glass $\rightarrow$ diopside crystalline, with heating temperature.

Fig. 3 shows the XRD pattern for the gel of \#S-1 after heating at $1473 \mathrm{~K}$ in air. The pattern is similar to that for

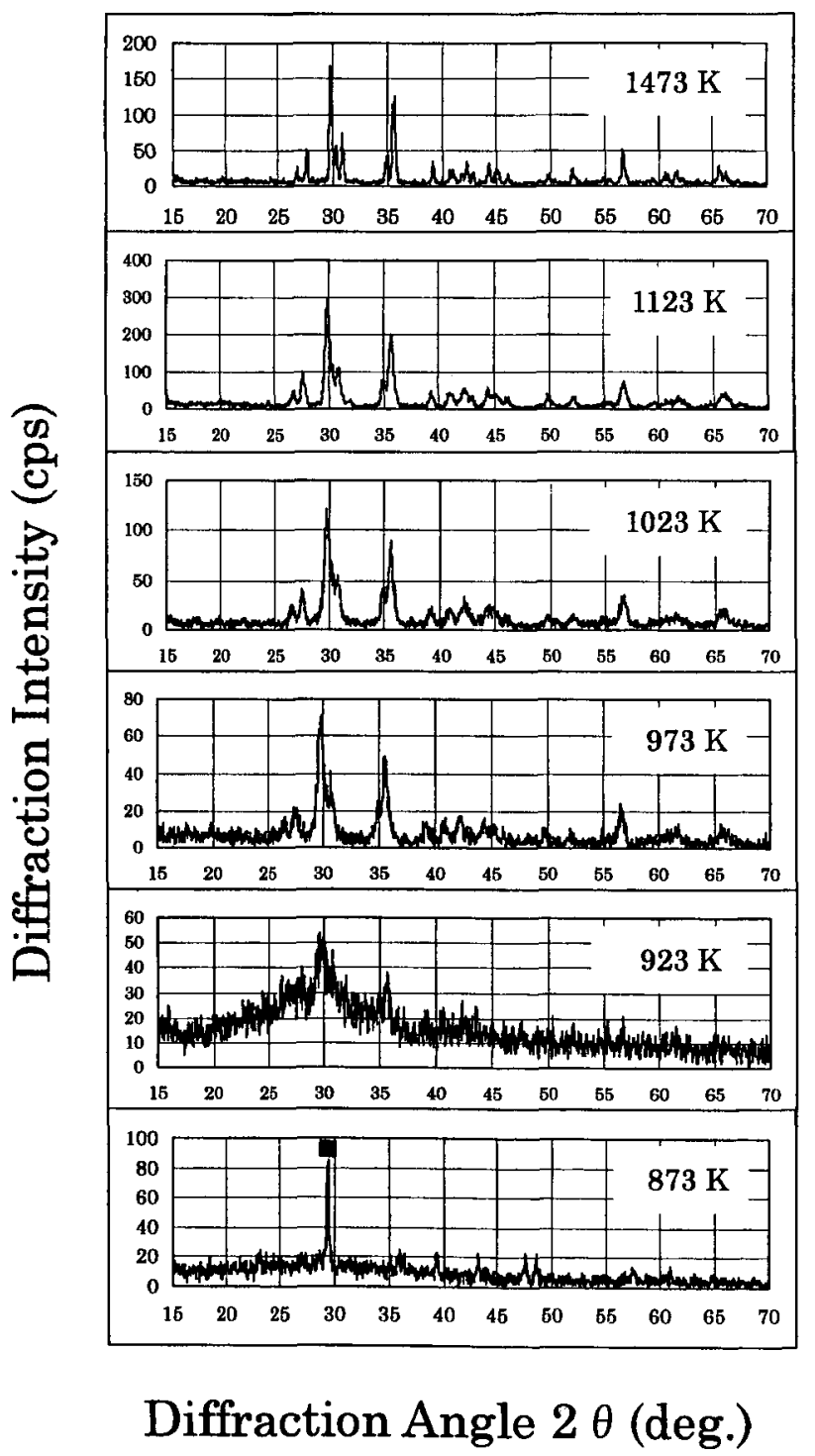

Fig.2 XRD pattern changes of dried gel of \#S-3 heated at various temperatures for $7.2 \mathrm{Ks}$ in air. $: \mathrm{CaCO}_{3}$ (calcite) 

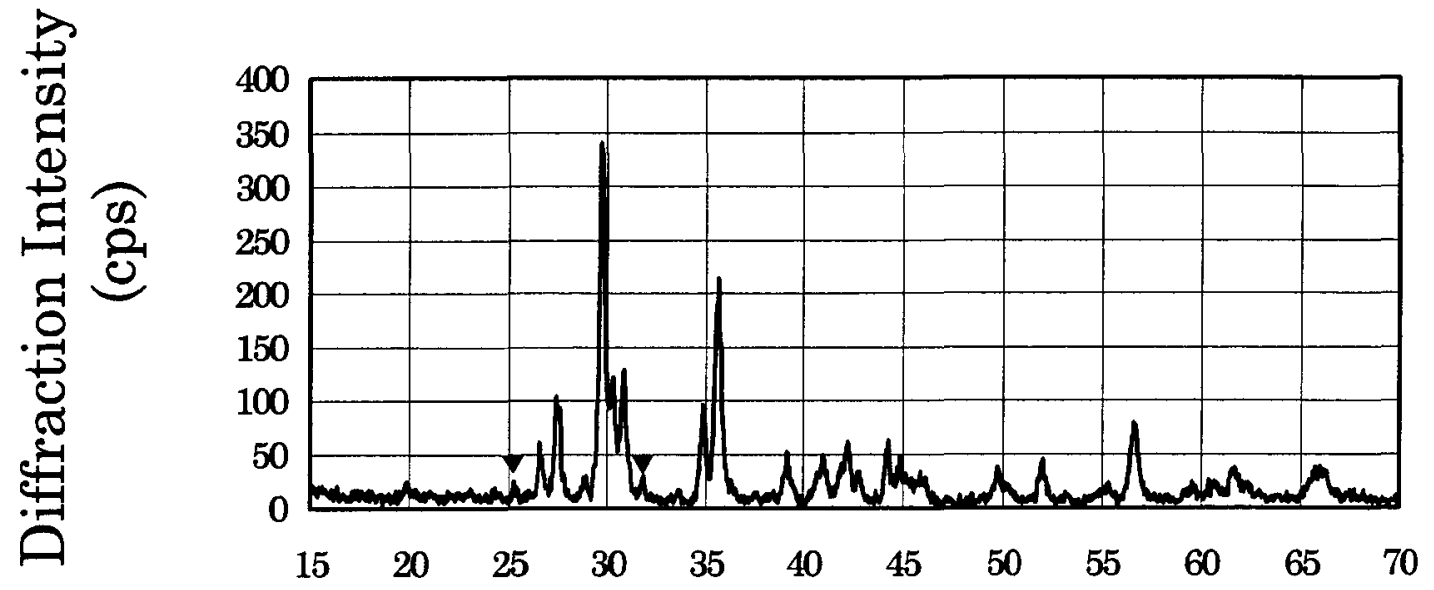

\section{Diffraction Angle $2 \theta$ (deg.)}

Fig. 3 XRD pattern of dried gel of \#S-1 heated at $1473 \mathrm{~K}$ for $7.2 \mathrm{Ks}$ in air. $\nabla: \alpha-\mathrm{CaSiO}_{3}$

the gel of \#S-3. However, $\alpha-\mathrm{CaSiO}_{3}$ is detectable ${ }^{6}$, although the peak intensity is weak. A trace amount of $\alpha-\mathrm{CaSiO}_{3}$ was also detected in the gel of \#S-2.

A crystallization sequence for the gel of \#S-6 prepared without adding hydrochloric acid, is given in Fig. 4. On heating at $623-873 \mathrm{~K}$, two polytype of calcium carbonate appears. Aragonite (JCPDS-50453) appears at 623-723 K and then changes to calcite at $823 \mathrm{~K}$. At $923 \mathrm{~K}$, calcite nearly disappears and a glassy diopside phase appears. Then, the crystallization begins at $1023 \mathrm{~K}$. Almost of the peaks at temperatures above $1023 \mathrm{~K}$ can be indexed as monoclinic diopside. However, a trace amount of $\alpha-\mathrm{CaSiO}_{3}$ is detected at $1273 \mathrm{~K}$.

The results of Figs. 1-3 suggest that addition of hydrochloric acid concentration above $3 \mathrm{~mol} / \mathrm{dm}^{3}$ realizes the single phase crystallization of only diopside. However, diopside crystalline prepared adding hydrochloric acid of $4 \mathrm{~mol}$ includes a considerable amount of chlorine, as confirmed by EPMA measurement. Thus, $3 \mathrm{~mol} / \mathrm{dm}^{3}$ is suitable for high purity of diopside ceramics.

Fig. 5 shows the XRD patterns for the four gels of \#S-1, \#S-2, \#S-3 and \#S-4 after heating at $923 \mathrm{~K}$ in air. The patterns show that \#S-1 is just before glass formation, \#S-2 is just before crystallization after completing glass formation, \#S-3 is just after crystallization and \#S-4 is almost completing crystallization. The results indicate that the crystallization temperature of the gels decreases with increasing the hydrochloric acid concentration. This agrees with the result of TG-DTA measurement.

From above results it is clear that the addition of hydrochloric acid restricts the formation of calcium

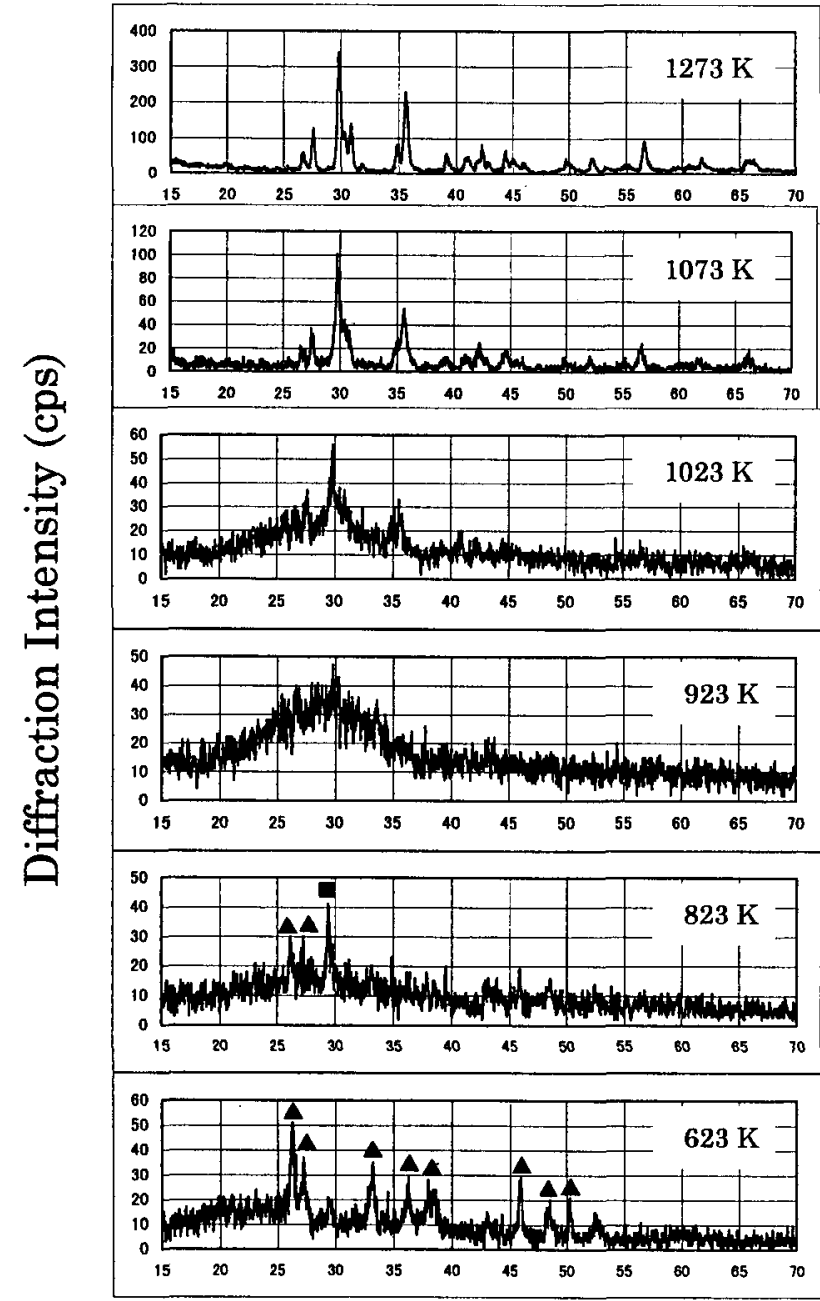

Diffraction Angle $2 \theta$ (deg.)

Fig.4 XRD pattern change of dried gel of \#S-6 heated at various temperatures for $7.2 \mathrm{Ks}$ in air.

: $\mathrm{CaCO}_{3}$ (calcite), $\mathrm{A}: \mathrm{CaCO}_{3}$ (aragonite) 




\section{Diffraction Angle $2 \theta$ (deg.)}

Fig.5 XRD patterns of dried gels heated at $923 \mathrm{~K}$ for $7.2 \mathrm{Ks}$ in air. (a) $1 \mathrm{~mol} / \mathrm{dm}^{3}$ (\#S-1), (b) $2 \mathrm{~mol} / \mathrm{dm}^{3}$ (\#S-2), (c) $3 \mathrm{~mol} / \mathrm{dm}^{3}$ (\#S-3), (b) $4 \mathrm{~mol} / \mathrm{dm}^{3}$ (\#S-4). $\mathrm{a}: \mathrm{CaCO}_{3}$ (calcite) carbonate and therefore prevents the delay of glass formation and crystallization by its existence. Calcium carbonate is formed by the reaction of the hydrolysed product, $\mathrm{Ca}(\mathrm{OH})_{2}$, with $\mathrm{CO}_{2}$ in air during gelation and/or glass formation by heating.

The structural change of the dried gels of \#S-3 in the heating process was also studied using ex-situ FTIR analysis. This spectral change with heating temperature was similar to $\mathrm{X}$-ray powder diffraction pattern change shown in Fig. 2. Fig. 6 shows the FTIR spectrum for the gel heated at $873 \mathrm{~K}$. The strong broad bands at about 3400 $\mathrm{cm}^{-1}$ and around $1650 \mathrm{~cm}^{-1}$ are attributed to water ${ }^{5}$. The absorption band around at $1020 \mathrm{~cm}^{-1}$, attributed to the $\mathrm{Si}-\mathrm{O}$ vibration in the $\mathrm{SiO}_{4}$ tetrahedron, shifted to $1070 \mathrm{~cm}^{-1}$ above $1023 \mathrm{~K}$. The absorption peak around $1430 \mathrm{~cm}^{-1}$ is attributed to the $\mathrm{CO}_{3}{ }^{2-}$ vibration from the presence of calcium carbonate $^{\text {?). }}$.

\section{Conclusions}

Effects of hydrochloric acid concentration on the crystallization of sol-gel derived $\mathrm{CaMgSi}_{2} \mathrm{O}_{6}$ gels prepared using a sol-gel route was investigated using TDA-TG, $\mathrm{X}$-ray diffraction and FTIR. It was found that the addition of hydrochloric acid leads to lower temperatures of glass formation and crystallization, due to the restriction of calcium carbonate formation, and that $3 \mathrm{~mol} / \mathrm{dm}^{3}$ is the suitable concentration for a single phase crystallization.

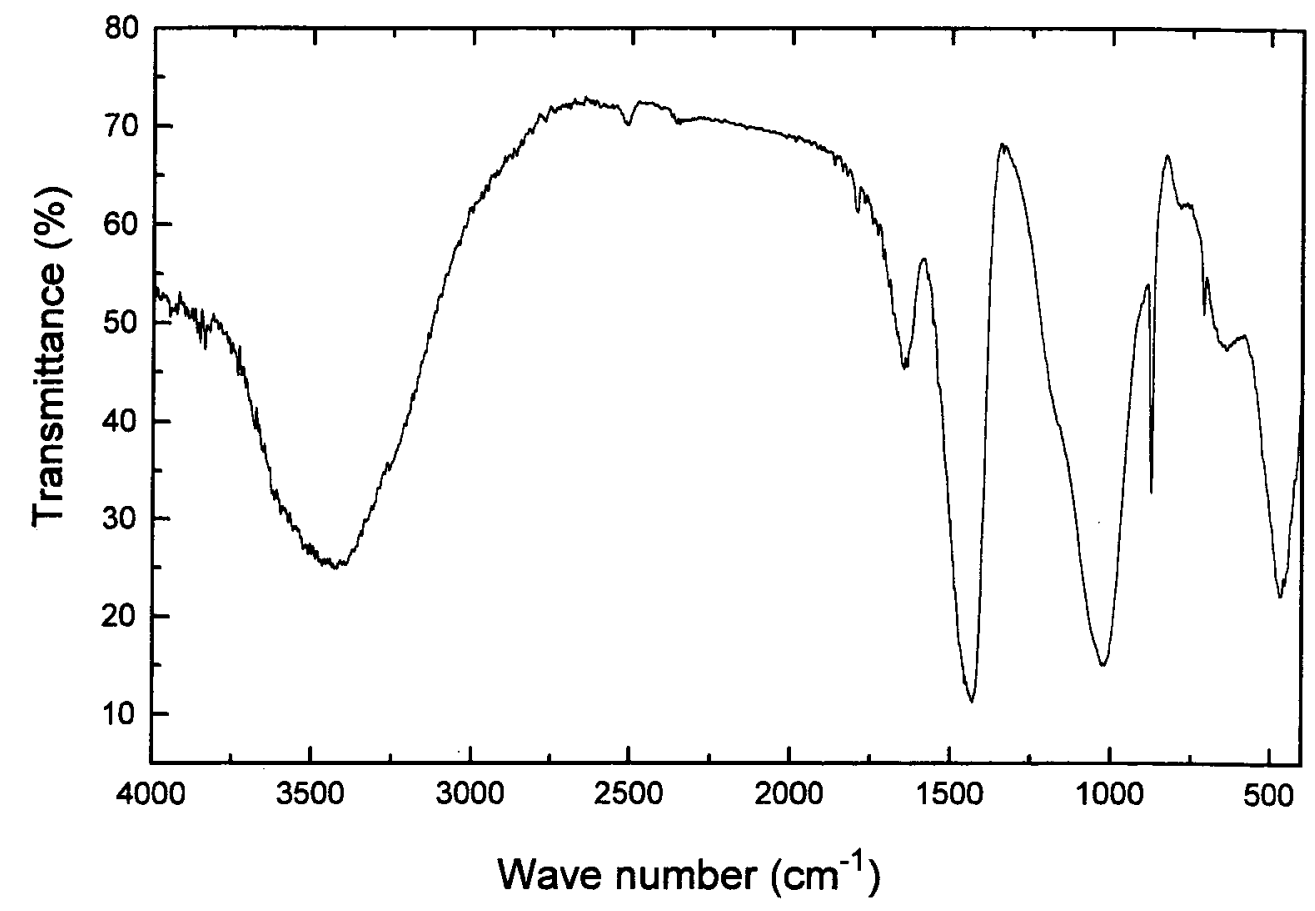

Fig.6 FTIR spectra of dried gels of \#S-3 heated at $873 \mathrm{~K}$ for $7.2 \mathrm{Ks}$ in air. 


\section{Acknowledgements}

The authors wish to thank Dr. Hideaki Ohtsuka for his measurement of DTA-TG.

\section{References}

1) T.Nonami: "Developmental Study of Diopside for Use as Implant Material", Mat. Res. Soc. Symp. Proc., 252 (1992)87-92.

2) T.Nonami, S.Tsutsumi, M.Fukuma and T.Urabe: "Mechanical Properties and Biocompatibility of Diopside", J. Jpn. Soc. Biomater., 12(1994)274-278.

3) Y.Miake, T.Yanagisawa, Y.Yajima, H.Noma, N.Yasui and T.Nonami: "High-resolution and Analytical Electron Microscopic Studies of New Crystals Induced by a Bioactive Ceramic (diopside)", J. Dent. Res., 74
(1995)1756-1763.

4) T.Nonami and S.Tsutsumi: "Preparation of PressFormable $\mathrm{CaO}-\mathrm{MgO}-\mathrm{SiO}_{2}-\mathrm{TiO}_{2}-\mathrm{Ag}_{2} \mathrm{O}$ Glass for Dental Crown", J. Ceramic Soc. Japan, 104(1996)201-207.

5) A.Katsui, K.Iwamoto and H.Ohtsuka: "Preparation and Characterization of Sol-Gel Derived $\mathrm{CaMgSi}_{2} \mathrm{O}_{6}$ Glass Ceramics", J. J. Japan Soc Powder and Powder Metallurgy, 46(1999)339-341.

6) A.Katsui, K.Iwamoto, H.Matsushita and H.Ohtsuka: "Effect of Hydrochloric Acid Catalyst on the Crystallization of Sol-Gel-Derived $\mathrm{CaMgSi}_{2} \mathrm{O}_{6}$ Gels", J. J. Japan Soc Powder and Powder Metallurgy, 46(1999)961-966.

7) T.Hayashi and H.Saito: "Preparation of $\mathrm{CaO}-\mathrm{SiO}_{2}$ Glasses by the Gel Method", J. Mater. Sci., 15(1980) 1971-1977. 